\title{
Metabolic engineering in Escherichia coli: lowering the lipoyl domain content of the pyruvate dehydrogenase complex adversely affects the growth rate and yield
}

\author{
Emma Dave, John R. Guest and Margaret M. Attwood
}

The Krebs Institute for Biomolecular Research, Department of Molecular Biology and

Biotechnology, University of Sheffield, PO Box 594, Firth Court, Western Bank, Sheffield S10 2UH, UK
Author for correspondence: Margaret M. Attwood. Tel: +441142768555 ext. 4405. Fax: +44 1142728697.

\begin{abstract}
Isogenic strains of Escherichia coli W3110 containing pyruvate dehydrogenase complexes with three (wild-type), two or one lipoyl domains per lipoate acetyltransferase (E2p) chain, were constructed. The maximum growth rates $\left(\mu_{\max }\right)$ for batch cultures growing in minimal medium containing different carbon sources showed that reducing the number of lipoyl domains adversely affects cell growth. The lower $\mu_{\max }$ value of the mutant containing one lipoyl domain per E2p chain was restored by the presence of compatible multicopy plasmids encoding PDH complexes with either one or three lipoyl domains per E2p chain. In glucose-limited chemostat cultures the protein contents of all strains were similar and substrate carbon was totally accounted for in the biomass and $\mathrm{CO}_{2}$ produced. However, the carbon efficiencies (percentage carbon conversion to biomass) were significantly lower when the lipoyl domain content of the E2p subunit was reduced from three to one. Similarly, the cellular maintenance energy $\left(m_{\odot}\right)$ and the maximum growth yield $\left(Y_{\max }\right)$ were lower in bacteria containing PDH complexes with fewer than three lipoyl domains per E2p chain. Wild-type values were restored by supplementing the medium with either casamino acids $(0.01 \%)$ or acetate (up to $0.1 \mathrm{mM}$ ). The lower growth efficiencies of the mutants were further confirmed in competition experiments where equal numbers of genetically marked (Naln) mutant and wild-type bacteria were used to inoculate glucose-limited chemostat cultures (dilution rate $0.075 \mathrm{~h}^{-1}$ ). The mutants with one or two lipoyl domains per E2p chain were washed out, whereas in controls, the initial ratio of wild-type (Nals) to reconstructed wild-type (Nalk) bacteria was maintained over $\mathbf{5 0}$ generations.
\end{abstract}

\section{Keywords: pyruvate dehydrogenase complex, metabolic engineering, Eschericbia coli,} lipoate acetyltransferase, lipoyl domains

\section{INTRODUCTION}

The pyruvate dehydrogenase (PDH) complex of Escherichia coli catalyses the NAD-dependent oxidative decarboxylation of pyruvate to acetyl-CoA by three integrated reactions (Guest et al., 1989; Perham, 1991; Mattevi et al., 1992). It contains multiple copies of the pyruvate dehydrogenase (E1p) and lipoamide dehydro-

Abbreviations: $D$, dilution rate; E1p, pyruvate dehydrogenase; E2p, lipoate acetyltransferase; E3, lipoamide dehydrogenase; PDH, pyruvate dehydrogenase (complex). genase (E3) components assembled on a 24-meric lipoate acetyltransferase (E2p) core with an approximate polypeptide stoichiometry of 24:24:12 (E1p:E2p:E3). The covalently bound lipoyl cofactors of the E2p subunits perform a central role in the catalytic mechanism, being in turn reductively acetylated, transacetylated and reoxidized at the respective E1p, E2p and E3 active sites. The PDH complex is expressed from the $p d b \mathrm{R}-a c e E F-l p d$ operon (Fig. 1) which encodes a pyruvate-responsive repressor, PdhR ( $p d h R)$, and the three enzymic subunits, E1p $(a c e E), \mathrm{E} 2 \mathrm{p}(a c e F)$ and E3 $(l p d)$. The operon is transcribed from the $p d b$ promoter located upstream of the $p d b R$ gene (Quail et al., 1994). There is a very weak 
promoter of unknown physiological significance in the $p d b R-a c e E$ intergenic region, and the distal gene $(l p d)$ is additionally transcribed from its own promoter, presumably to meet the E3 requirements of the 2oxoglutarate dehydrogenase complex and the glycine cleavage system. Mutations in the ace $E$ and $a c e F$ genes lead to a iequirement for acetate during aerobic growth on glucose, $l p d$ mutants require acetate plus succinate for best aerobic growth, and $p d b \mathrm{R}$ mutants synthesize the PDH complex at a constitutive (pyruvate non-inducible) level.

The E2p chain contains five independently folded domains joined by flexible linkers. The domains include: three highly homologous 80-residue lipoyl domains (each with a lipoylatable lysine residue); an internal 50-residue E3-binding domain; and a C-terminal 250-residue coreforming and E1p-binding domain containing the lipoate acetyltransferase catalytic site (Guest $e$ t al., 1989; Perham, 1991). A similar segmented organization occurs in the respective E2p, E2o and E2b subunits of the pyruvate, 2oxoglutarate and branched chain 2-oxo acid dehydrogenase complexes from a variety of sources, but there are differences in the lipoyl domain contents. Thus, whereas the E. coli and Azotobacter vinelandii PDH complexes contain three lipoyl domains per E2p chain, the E2p chains of Streptococcus faecalis and mammalian mitochondria contain two, and the E2p chains of Bacilli and yeast contain only one, like the E2o and E2b chains from both prokaryotic and eukaryotic sources (Perham, 1991). It is not clear why the E2p chains of $E$. coli and $A$. vinelandii have three lipoyl domains. Indeed, the selective deletion of aceF sub-segm_.its (1lip or 2lip) encoding one or two net lipoyl domains so as to generate operons that express PDH complexes containing two or one hybrid lipoyl domains per E2p chain (2lip- and 1lip-PDH complexes), has little effect on the specific activities of the purified complexes relative to the wild-type, 3lip-PDH, complex (Guest et al., 1985; Graham et al., 1986). It is also apparent that multicopy ace $E F-l p d$ plasmids containing ace $F$ genes with 1lip and 2lip segments, fully complement the nutritional lesions of a $p d b R$-aceEF-lpd deletion strain. It has likewise been found that about half of the lipoyl domains can be proteolytically cleaved from the PDH comple .itiout significant loss of catalytic activity, and that chemical inactivation or enzymic removal of the lipoyl groups has a non-linear (disproportionately lower) effect on catalytic activity (Stepp et al., 1981; Berman et al., 1981). This is attributed to the process of active-site coupling in which the rate-limiting E1p subunits can interact with more than one of the many lipoyl domains, which themselves participate in an extensive network of intramolecular transacetylation reactions. The acetyl groups and reducing equivalents can thus take many routes through the complex before transfer to $\mathrm{CoA}$ and $\mathrm{NAD}$, and the function of a particular lipoyl domain can be adopted by others of the apparently superfluous number of such domains (reviewed by Perham, 1991). More recently, studies with PDH complexes containing four to nine lipoyl domains per E2p chain have shown that activity decreases with increasing numbers of lipoyl domains, possibly due to under-lipoylation of the domains participating in catalysis and to interference from unlipoylated domains (Machado et al., 1992).

An important facilitator of active-site coupling and hence catalytic efficiency, is the mobility conferred by the interdomain linkers. This is apparent from the loss of activity which ultimately occurs when the linkers in a 1lip-PDH complex are shortened or replaced (Miles et al., 1988; Turner et al., 1993). High-field NMR studies with PDH complexes containing zero to nine lipoyl domains per E2p chain, have recently indicated that the wild-type arrangement (3lip-PDH complex) provides the highest degree of mobility, in terms of the ratio of lipoyl linker mobility to lipoyl domain mobility, and presumably the highest catalytic efficiency (Machado et al., 1993). It would appear that the predicted higher catalytic efficiency of the 3 lip-PDH complex relative to the 1lip- and 2lip-PDH complexes is not reflected in the observed active-site coupling abilities (an equilibrium assay) nor in the specific activities measured under substrate-saturating conditions, but it may be revealed by detailed kinetic studies under substrate-limiting conditions. The latter is made difficult by the need to amplify and purify different complexes so that they each have identical subunit stoichiometries and identical degrees of lipoylation, in order to make valid comparisons.

Here, an alternative approach has been used to investigate whether, contrary to evolutionary pressure or the normal principle of parsimony in biomolecular assembly (Perham, 1991), E. coli elaborates a PDH complex containing more than sufficient lipoyl domains to satisfy its requirements under a range of growth conditions. This involved constructing stable isogenic strains which have chromosomal $p d b \mathrm{R}$-aceEF-lpd operons that encode 1lip-, 2lipand 3lip-PDH complexes. Physiological comparisons with these strains has provided evidence that the molecular-genetic lowering of the lipoyl domain content of the PDH complex adversely affects the growth rate and yield of E. coli.

\section{METHODS}

Bacterial strains and plasmids. The prototrophic strain of $E$. coli $\mathrm{K} 12$ used as the wild-type or parental strain was W3110 (iclR $\operatorname{trpR})$, and JRG2930 (aceF::kan ${ }^{\mathrm{R}}$ ) is a derivative in which the ace $F$ gene was inactivated by the net deletion of two lip segments (encoding two net lipoyl domains) and the insertion of a $\mathrm{kan}^{\mathrm{R}}$ cassette into the residual lip segment. JRG2930N is a spontaneous $\mathrm{Nal}^{\mathrm{R}}$ mutant of JRG2930, selected on $\mathrm{L}$ agar plus nalidixic acid. Further isogenic derivatives of JRG2930N in which the ace $F:: k a n^{\mathrm{R}}$ region was replaced by ace $F$ genes encoding E2p subunits with one to three lipoyl domains are: JRG2931 (1lip); JRG2932 (2lip); and JRG2933 (3lip). Some details of key bacterial strains and relevant plasmids are given in Table 1 and Fig. 1. Several pBR322 derivatives (pGS101, pGS102 and pGS104) were used as sources of the KpnI-SpbI fragments containing ace $E F^{\prime}$ cassettes with different numbers of lip segments, that were transferred to the thermosensitive replicon (pMAK705) prior to allelic replacement. Other plasmids (pGS87 and pGS110) that express wild-type and modified ace $E F-l p d$ genes from the weak ace promoter in the 
Three lipoyl domains are better than two or one

Table 1. Bacterial strains and plasmids

\begin{tabular}{|c|c|c|}
\hline $\begin{array}{l}\text { Strain or } \\
\text { plasmid }\end{array}$ & Relevant characteristics* & \\
\hline \multicolumn{3}{|l|}{ Strain } \\
\hline W3110 & Prototroph; $\mathrm{Nal}^{\mathrm{S}}$ & \\
\hline JRG2930N & Derivative of W3110 with a disrupted 1 lip ace $F$ gene $\left(a c e F:: k a n^{\mathrm{R}}\right) ; \mathrm{Nal}^{\mathrm{R}}$ & This work \\
\hline JRG2931-3 & Derivatives of JRG2930N with reconstructed 1-3lip aceF genes; $\mathrm{Nal}^{\mathrm{R}}$ & This work \\
\hline \multicolumn{3}{|l|}{ Plasmid } \\
\hline pGS87 & pBR322 derivative containing aceEF-lpd operon encoding a 3lip-E2p; Ap ${ }^{\mathbf{R}}$ & Guest et al. (1985) \\
\hline pGS101 & pBR322 with 3 lip ace $E F^{\prime}$ fragment; Ap ${ }^{\mathrm{R}}$ & Guest et al. (1985) \\
\hline pGS102 & pBR322 with 2 lip ace $E F^{\prime}$ fragment; Ap ${ }^{\mathrm{R}}$ & Guest et al. (1985) \\
\hline pGS104 & pBR322 with 1 lip ace $E F^{\prime}$ fragment; Ap ${ }^{R}$ & Guest et al. (1985) \\
\hline pGS110 & pBR322 containing aceEF-lpd operon encoding a 1lip-E2p; Ap ${ }^{\mathbf{R}}$ & Guest et al. (1985) \\
\hline pGS459 & pGS104 with ace $E F^{\prime}:: k a n^{\mathbf{R}}$ fragment; $\mathrm{Ap}^{\mathbf{R}} \mathrm{Km}^{\mathrm{R}}$ & This work \\
\hline pMAK705 & $\operatorname{Rep}_{t s} \mathrm{Cm}^{\mathrm{R}}$ & Hamilton et al. (1989) \\
\hline pGS522 & pMAK705 with ace $E F^{\prime}:: k a n^{\mathbf{R}}$ fragment from pGS459; rep ${ }_{t s} \mathrm{Cm}^{\mathbf{R}} \mathrm{Km}^{\mathbf{R}}$ & This work \\
\hline pGS741 & pMAK705 with 1lip ace $E F^{\prime}$ from pGS104; rep $\mathrm{p}_{\mathrm{ts}} \mathrm{Cm}^{\mathrm{R}}$ & This work \\
\hline pGS742 & pMAK705 with 2 lip ace $E F^{\prime}$ from pGS102; rep $_{t s} \mathrm{Cm}^{\mathbf{R}}$ & This work \\
\hline pGS743 & pMAK705 with 3 lip ace $E F^{\prime}$ from pGS101; rep $\mathrm{Cm}^{\mathbf{R}}$ & This work \\
\hline
\end{tabular}

* lip denotes a segment of the ace $F$ gene that encodes a lipoyl domain.

$p d h \mathrm{R}-a c e E$ intergenic region, were used in complementation studies.

Media and culture methods. The rich medium used for routine subcultures was L broth (Lennox, 1955) which contains glucose $(0 \cdot 1 \%)$, supplemented with chloramphenicol, kanamycin, nalidixic acid or ampicillin (each at $20 \mu \mathrm{g} \mathrm{ml}^{-1}$ ), as required. The minimal medium used in nutritional tests was the citratecontaining medium E of Vogel \& Bonner (1956) with glucose $(20 \mathrm{mM})$ or potassium succinate $(40 \mathrm{mM})$ as carbon source, with or without a supplement of sodium acetate $(2$ or $4 \mathrm{mM})$, and agar $1.5 \%(\mathrm{w} / \mathrm{v})$. Cultures were streaked to single colonies (one culture per plate) and growth was recorded at intervals for up to $72 \mathrm{~h}$. The minimal medium used for batch cultures had the following composition $\left(\mathrm{g} \mathrm{l}^{-1}\right)$ : $\left(\mathrm{NH}_{4}\right)_{2} \mathrm{SO}_{4}, 2 \cdot 0 ; \mathrm{K}_{2} \mathrm{HPO}_{4}, 1 \cdot 0$; $\mathrm{NaH}_{2} \mathrm{PO}_{4} \cdot 3 \mathrm{H}_{2} \mathrm{O}, 1 \cdot 3 ; \mathrm{MgSO}_{4} .7 \mathrm{H}_{2} \mathrm{O}, 0.2$; with trace elements solution (Vishniac \& Santer, 1957), $2.0 \mathrm{ml}$; and the stated carbon source. The standard medium used for carbon (glucose)limited chemostat cultures was that described by Brooke et al. (1989) without the vitamin solution. It differs from the medium used for batch cultures only in containing less phosphate $\left(\mathrm{K}_{2} \mathrm{HPO}_{4}, 1 \cdot 0 \mathrm{~g} \mathrm{l}^{-1}\right)$ since less buffering capacity is required.

Batch cultures were used to determine doubling times and hence $\mu_{\max }$ values of different cultures by monitoring the $\mathrm{OD}_{430}$ (Pye Unicam SP6-250) of triplicate cultures ( $50 \mathrm{ml}$ in $250 \mathrm{ml}$ flasks) shaken at $37^{\circ} \mathrm{C}$. The inocula were pre-grown in the same medium, washed with carbon-free medium and resuspended in the growth medium. The slopes of $\log \mathrm{OD}_{430}$ versus time plots were determined by regression analysis in the exponential regions and used to calculate $\mu_{\max }$ values.

Chemostat cultures were grown in chemostat vessels (1 litre nominal; working volumes 700 and $750 \mathrm{ml}$ ) maintained at $37^{\circ} \mathrm{C}$. The $\mathrm{pH}$ was adjusted to $6.9 \pm 0 \cdot 1$ by automatic titration with $2 \mathrm{M} \mathrm{KOH}$. Dissolved $\mathrm{O}_{2}$ levels were monitored with galvanic oxygen electrodes. The culture agitation speed (500750 r.p.m.) and air flow $\left(500-1000 \mathrm{ml} \mathrm{min}^{-1}\right)$ were adjusted to maintain a dissolved $\mathrm{O}_{2}$ concentration above $50 \%$ air saturation. The inocula were grown overnight in the same medium.
DNA manipulation and Southern blotting. DNA was prepared and manipulated by standard procedures (Sambrook et al., 1989). For Southern blotting, (HindIII or PvuII) digests of bacterial DNA were fractionated by electrophoresis in $0.7 \%$ agarose-Tris/acetate-EDTA gels and transferred to nitrocellulose membranes (Sambrook et al., 1989). The blots were hybridized for $18 \mathrm{~h}$ at $68^{\circ} \mathrm{C}$ with $5 \times$ SSC and washed twice for 5 min at $20^{\circ} \mathrm{C}$ with $2 \times$ SSC $+0.1 \%$ SDS and then twice for 15 min at $65^{\circ} \mathrm{C}$ with $0.1 \times \mathrm{SSC}+0.1 \%$ SDS $(1 \times$ SSC contains $0 \cdot 15 \mathrm{M}$ sodium chloride and $0 \cdot 015 \mathrm{M}$ sodium citrate, $\mathrm{pH} 7 \cdot 0$ ). Digoxygenin-labelled probes containing the $1.26 \mathrm{~kb} \mathrm{Km}{ }^{R}$ cassette (PstI digest of pGS459), the $1.68 \mathrm{~kb}, K p n \mathrm{I}-S p b \mathrm{I}$ fragment from pGS104 encoding part of the E1p chain linked to a 1 lip-E2p chain (see Fig. 1), or the $2 \cdot 28 \mathrm{~kb} K p n \mathrm{I}-S p h \mathrm{I}$ fragment from pGS101 encoding an analogous segment with a 3lip-E2 chain, were used. The corresponding restriction fragments were extracted from low-melting-point agarose gel after electrophoresis, and used in hybridization and detection procedures, as described by the manufacturers.

Preparation of cell-free extracts and enzyme assays. Cultures were grown to mid-exponential phase, harvested, washed and resuspended at $1 \mathrm{~g}$ per $4 \mathrm{ml}$ cold potassium phosphate buffer $(20 \mathrm{mM}, \mathrm{pH} 7 \cdot 0)$ containing disodium EDTA $(2 \mathrm{mM})$, PMSF $(1 \mathrm{mM})$ and benzamidine hydrochloride $(1 \mathrm{mM})$. The cell suspension was cooled to $4{ }^{\circ} \mathrm{C}$ and then disrupted by ultrasonic treatment (MSE disintegrator $150 \mathrm{~W}$ ) of $15 \times 30 \mathrm{~s}$ pulses interspersed with $30 \mathrm{~s}$ cooling periods. Intact bacteria and cell debris were removed by centrifugation $\left(25000 \mathrm{~g}, 30 \mathrm{~min}, 4^{\circ} \mathrm{C}\right)$. The clear supernatant fluid was used as the crude cell-free extract.

The specific activities of the $\mathrm{PDH}$ complex and individual components were measured by standard procedures (Russell \& Guest, 1990). The observed rates were proportional to the amounts of added cell-free extract and linear for at least 3 min. One enzyme unit (U) is defined as the amount of enzyme that catalyses the formation of $1 \mu \mathrm{mol}$ product or the reduction of $1 \mu \mathrm{mol}$ coenzyme per $\mathrm{h}$ at $37^{\circ} \mathrm{C}$; specific enzyme activities are defined as $\mathrm{U}$ (mg protein) $)^{-1}$. 
Analytical methods. Glucose in feed medium and culture filtrates was measured enzymically using glucose oxidase (Bergmeyer \& Bernt, 1974). Low-molecular-mass overmetabolites in culture filtrates were measured by HPLC with a Shodex Ion pakKC-811 column $(8 \times 300 \mathrm{~mm})$ at $50^{\circ} \mathrm{C}$. Samples were eluted with $0 \cdot 1 \%$ phosphoric acid at a flow rate of $2 \mathrm{ml}$ $\mathrm{min}^{-1}$ through detectors for UV $(210 \mathrm{~nm})$ and refractive index (Waters $490 \mathrm{E}$ and 410 , respectively) coupled in tandem to a data module (Millennium 2010); the peak areas were proportional to concentration. Protein concentrations in whole cells and in cellfree extracts were measured by the Lowry method with BSA as the standard.

Metabolic rates and carbon recovery. Glucose consumption, $\mathrm{O}_{2}$ consumption and $\mathrm{CO}_{2}$ production rates $\left(q_{\mathrm{Glc}}, q_{\mathrm{o}_{2}}\right.$ and $q_{\mathrm{CO}_{2}}$, respectively), carbon conversion efficiencies and carbon balances were calculated as described by Brooke et al. (1989). The specific growth rates of the out-competed population in the competition experiments were calculated using a modified washout growth rate equation (Jannasch, 1969).

Materials. Restriction enzymes were from Northumbria Biochemicals, the $\mathrm{Km}^{\mathrm{R}}$ GenBlock was from Pharmacia, and the Non-radioactive Digoxygenin Labelling Kit was from Boehringer Mannheim.

\section{RESULTS}

\section{Construction of isogenic strains with modified acef genes encoding E2p subunits with one, two or three lipoyl domains}

An isogenic set of strains containing restructured ace $F$ genes was obtained by a combination of site-specific mutation (in vitro) and allelic replacement (in vivo) using a temperature-sensitive replicon (pMAK705; Hamilton et al., 1989). In a three-phase strategy, the lip region of an aceF gene encoding a 1lip-E2p subunit was first disrupted by inserting a kan ${ }^{\mathbf{R}}$ cassette in vitro. The corresponding chromosomal aceF segment (3lip) was then replaced by the disrupted aceF::kan ${ }^{\mathbf{R}}$ segment in vivo, and finally the chromosomal ace $F: k_{k a n}{ }^{\mathrm{R}}$ region was replaced by segments of DNA encoding E2p subunits with one, two or three lipoyl domains. The plasmid (pGS104) encoding part of a 1lip-E2p subunit was first cleaved at a unique $B c l \mathrm{I}$ site in the lip region and the $k a n^{\mathrm{R}}$ gene $(1.27 \mathrm{~kb}$ Bam HI fragment from $\mathrm{Km}^{\mathrm{R}}$ GenBlock) was inserted with known orientation, to generate pGS459 (Fig. 1). The aceF::kan ${ }^{\mathbf{R}}$ region was then transferred to pMAK 705 by inserting the $K p n \mathrm{I}-S p h \mathrm{I}$ fragment into the corresponding sites of the polylinker to generate pGS522 (Fig. 1).

In the second stage, plasmid co-integrants arising by the homologous recombination between plasmid and chromosome were obtained by transforming $E$. coli W3110 with pGS522 and selecting $\mathrm{Cm}^{\mathbf{R}}$ and $\mathrm{Km}^{\mathbf{R}}$ colonies at $42{ }^{\circ} \mathrm{C}$ (Hamilton et al., 1989). The cointegrants represented $1.4 \%$ of comparable transformants selected at $30^{\circ} \mathrm{C}$ and after purification, five to ten independent cointegrants were inoculated into $\mathrm{L}$ broth $(100 \mathrm{ml})$ containing both antibiotics and grown at $30{ }^{\circ} \mathrm{C}$ to allow resolution by a second recombination event. $\mathrm{Km}^{\mathbf{R}}$ colonies were then selected at $42{ }^{\circ} \mathrm{C}$ and screened first for $\mathrm{Cm}^{\mathrm{s}}$ at $30^{\circ} \mathrm{C}$ to ensure that the pMAK705 replicon had been eliminated, and then nutritionally for $\mathrm{Ace}^{-}$res- olution products. After enzymological tests and Southern blotting with ace and kan probes to ensure that the $a c e F:: k a n^{\mathbf{R}}$ cassette had been incorporated at the desired chromosomal site (see below), a representative mutant (JRG2930) and a spontaneous nalidixic acid resistant derivative thereof (JRG2930N, Fig. 1), were retained. The $\mathrm{Nal}^{\mathrm{R}}$ marker served in later studies to distinguish between engineered and wild-type strains.

In the final stage, the chromosomal aceF::kan ${ }^{\mathbf{R}}$ region was replaced by analogous ace $F$ segments from plasmids encoding one (pGS741), two (pGS742) or three (pGS743) lipoyl domains (Fig. 1). The same replacement strategy involving the thermosensitive $\mathrm{Cm}^{\mathrm{R}}$ replicon was adopted, except that batches of transformant colonies $(\geqslant 30)$ were grown for two successive periods of $16 \mathrm{~h}$ at $42^{\circ} \mathrm{C}$ in $\mathrm{L}$ broth containing both antibiotics, before inoculating into $\mathrm{L}$ broth plus chloramphenicol $(0.5 \mathrm{ml}$ inoculum in $50 \mathrm{ml}$ culture) and growing at $30^{\circ} \mathrm{C}$ to allow cointegrate resolution. Nalidixic acid resistant colonies, selected on $\mathrm{L}$ agar at $42{ }^{\circ} \mathrm{C}$ to ensure elimination of the thermosensitive replicon, were screened first for $\mathrm{Cm}^{\mathrm{s}} \mathrm{Km}^{\mathrm{s}}$ products at $30{ }^{\circ} \mathrm{C}$, and then for $\mathrm{Cm}^{\mathrm{S}} \mathrm{Km}^{\mathrm{S}} \mathrm{Ace}^{+}$derivatives. The desired $\mathrm{Ace}^{+}$strains, potentially having one, two and three lipoyl domains per E2p chain, were recovered at rather low frequencies $(1 / 195,3 / 12119$ and $3 / 13500$, respectively). These low frequencies probably reflect the relatively short regions of homology between the incoming and resident segments of DNA (1.54 and $0.44 \mathrm{~kb})$. The predicted replacements were confirmed for all of the $\mathrm{Ace}^{+}$derivatives by Southern blotting using kan and ace probes with diagnostic digests of chromosomal DNA (see Methods). Positive hybridization of the ace probe to chromosomal PvuII fragments of $2 \cdot 05,0 \cdot 7,1.07$ or $1.38 \mathrm{~kb}$ $\left(\mathrm{L}_{\mathrm{K}}, \mathrm{L}_{1}, \mathrm{~L}_{2}\right.$ or $\mathrm{L}_{3}$ in Fig. 1) was diagnostic either for the retention of the aceF::kan ${ }^{\mathrm{R}}$ region of JRG2930N, or for the presence of an ace $F$ gene with one, two or three lip segments (respectively). Likewise with the kan probe, hybridization was observed with two HindIII fragments (2.05 and $0.6 \mathrm{~kb} ; \mathrm{K}_{\mathrm{A}}$ and $\mathrm{K}_{\mathrm{B}}$ in Fig. 1) using DNA from JRG2930N, whereas the lack of hybridization with the other strains confirmed that the kan ${ }^{\mathbf{R}}$ cassette had been eliminated. Ultimately, this yielded the representative set of isogenic JRG2930N derivatives having chromosomal $p d b R-a c e E F-l p d$ operons encoding 1lip- (JRG2931), 2lip- (JRG2932) and 3lip- (JRG2933) PDH complexes, as listed in Fig. 1.

\section{Characterization of strains}

The physiological consequences of lowering the lipoyl domain content of the PDH complex was investigated by nutritional and enzymological tests. Plate growth tests at temperatures ranging from 30 to $44^{\circ} \mathrm{C}$, with the wildtype (W3110), the insertion mutant (JRG2930N) and the isogenic set of 1-3lip derivatives (JRG2931-3), were monitored over a period of $72 \mathrm{~h}$ (Table 2). As expected, the ace $F:: k^{R}{ }^{R}$ insertion mutant was unable to grow in medium containing glucose or succinate as sole carbon source unless supplemented with acetate, and the ability to grow on unsupplemented medium was restored when 


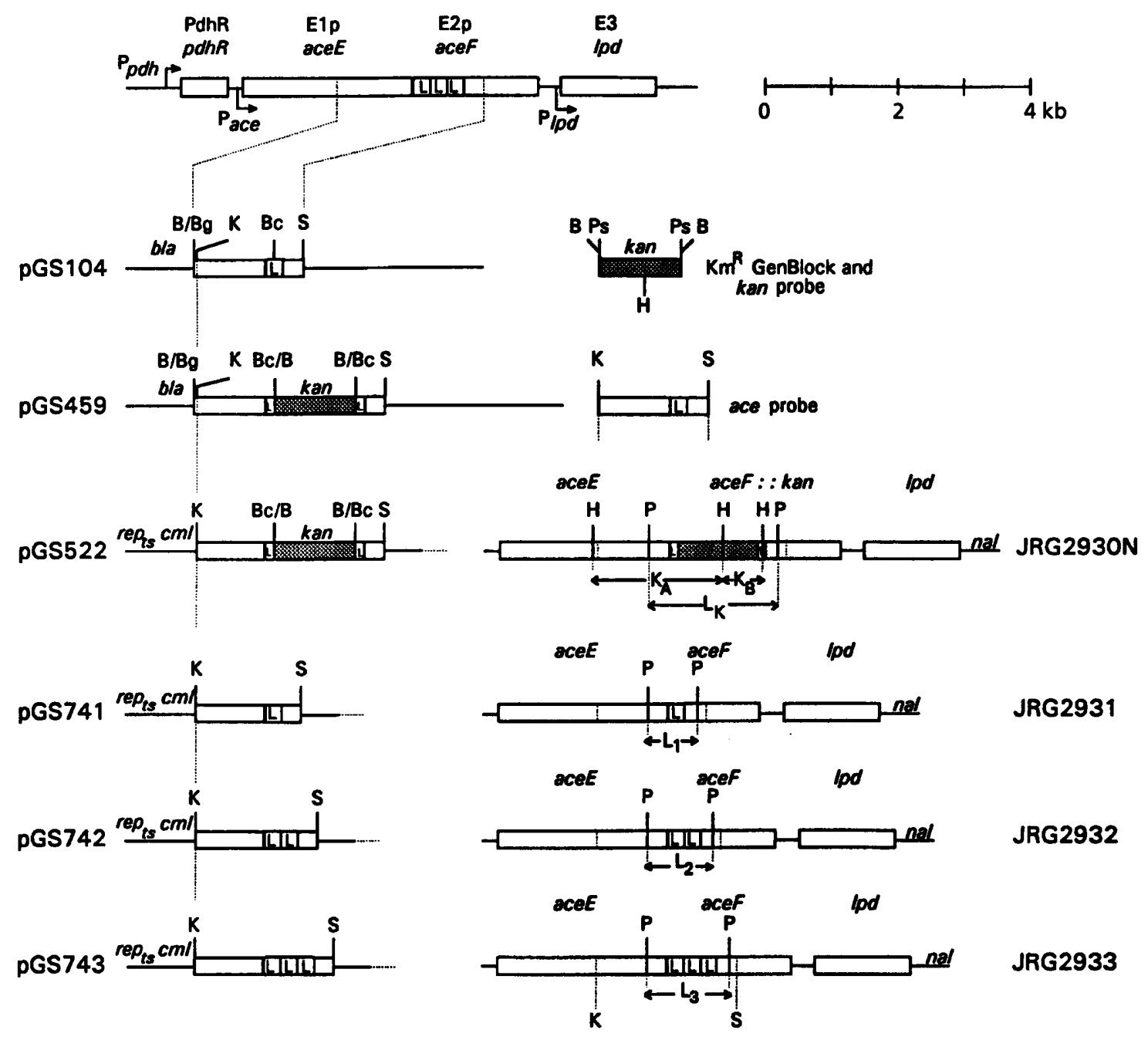

Fig. 1. Organization of the pdhR-aceEF-Ipd operon of $E$. coli and strategy for constructing isogenic derivatives with one, two and three lipoyl domains per lipoate acetyltransferase chain (E2p) in the corresponding PDH complexes. The genes, gene-products and promoters in the wild-type operon, where the acef gene has 3lip segments, are shown at the top. The lip segments of the aceF genes are marked (L). Derivatives of the thermosensitive replicon, MAK705 (rep $\mathrm{ts}_{\mathrm{ts}} \mathrm{cm}$, containing modified ace'EF' fragments used for inactivating and reactivating the chromosomal ace $F$ gene are shown on the left. Segments of the restructured operons in the corresponding bacterial strains are shown on the right. The DNA fragments used as kan and ace probes in Southern blotting, and the diagnostic fragments to which they hybridize, are indicated $\left(\mathrm{K}_{\mathrm{A}}, \mathrm{K}_{\mathrm{B}}\right.$ and $\left.\mathrm{L}_{1-3}\right)$. Relevant restriction sites: $\mathrm{B}, \mathrm{BamHI} ; \mathrm{BC}, \mathrm{BCll}$; Bg, Bglll; H, Hindlll; $\mathrm{K}, \mathrm{Kpnl}$; P, Pvull; Ps, Pstl, $\mathrm{S}$, Sphl.

the disrupted ace $F$ gene was replaced by those encoding E2p chains with one, two or three lipoyl domains. Temperature-sensitive growth was observed with JRG2930N and its derivatives, in some media at or above $42{ }^{\circ} \mathrm{C}$ (Table 2). The reason for this is unknown, especially as it was not detected with W3110 (except in succinate minimal medium), and it was not specifically correlated with the lipoyl domain complement. Nevertheless, at the temperature used in this study $\left(37^{\circ} \mathrm{C}\right)$ all of the strains except for JRG2930N exhibited the same growth patterns. It can also be concluded that the nutritional complementation of the $\mathrm{Ace}^{-} \mathrm{Lpd}^{-}$phenotypes of an aroP-lpd deletion strain by plasmids expressing 1lip- and 2lip$\mathrm{PDH}$ complexes, observed in previous growth tests
(Guest $e t$ al., 1985), is not dependent on the presence of multiple rather than single copies of the restructured operons. Enzymological tests with crude cell-free extracts of mid-exponential phase cultures grown at $37^{\circ} \mathrm{C}$, confirmed that all of the $\mathrm{Ace}^{+}$strains contain active PDH complexes and component enzymes (E1p, E2p and E3), whereas the aceF::kan ${ }^{\mathrm{R}}$ insertion mutant (JRG2930N) lacks both lipoate acetyltransferase (E2p) and $\mathrm{PDH}$ complex activities (Table 2). The specific activities were measured in the presence of excess substrates under optimal conditions, and although directly comparable with each other and other related studies, the absolute values do not necessarily reflect the corresponding in vivo activities. 
Table 2. Nutritional and enzymological characterization of isogenic strains with different lipoyl domain contents in their PDH complexes

Growth of cultures on solid media was observed at a range of temperatures $\left(30-44{ }^{\circ} \mathrm{C}\right)$ over $72 \mathrm{~h}$. The relative extents of growth in different media was recorded as $(-)$ no growth, $(+)$ some growth, and $(++)$ good growth; no growth was observed at or above the temperature shown in parentheses. The enzyme specific activities of crude cell-free extracts are each based on measurements taken at three rate-determining protein concentrations.

\begin{tabular}{|c|c|c|c|c|c|c|c|c|}
\hline \multirow[t]{2}{*}{ Strain } & \multicolumn{4}{|c|}{ Carbon source (and supplement) } & \multicolumn{4}{|c|}{ Specific activity [U (mg protein) $\left.)^{-1}\right]$} \\
\hline & Glucose & $\begin{array}{l}\text { Glucose } \\
\text { (acetate) }\end{array}$ & Succinate & $\begin{array}{c}\text { Succinate } \\
\text { (acetate) }\end{array}$ & $\begin{array}{c}\text { PDH } \\
\text { complex }\end{array}$ & E1p & E2p & E3 \\
\hline W3110 & ++ & ++ & $+\left(44^{\circ} \mathrm{C}\right)$ & + & $4 \cdot 2$ & $1 \cdot 9$ & $66 \cdot 0$ & 338 \\
\hline $\begin{array}{l}\text { JRG2930N } \\
\left(a c e F:: k a n^{\mathrm{R}}\right)\end{array}$ & - & $++\left(44^{\circ} \mathrm{C}\right)$ & - & + & $<0.001$ & $0 \cdot 4$ & $<0.01$ & 117 \\
\hline JRG2931 (1lip) & $++\left(44^{\circ} \mathrm{C}\right)$ & $++\left(44^{\circ} \mathrm{C}\right)$ & $+\left(42{ }^{\circ} \mathrm{C}\right)$ & $+\left(44^{\circ} \mathrm{C}\right)$ & $9 \cdot 0$ & $1 \cdot 5$ & $49 \cdot 8$ & 301 \\
\hline JRG2932 (2lip) & $++\left(42^{\circ} \mathrm{C}\right)$ & $++\left(42^{\circ} \mathrm{C}\right)$ & $+\left(42^{\circ} \mathrm{C}\right)$ & + & $4 \cdot 3$ & 0.7 & $31 \cdot 8$ & 189 \\
\hline JRG2933 (3lip) & $++\left(44^{\circ} \mathrm{C}\right)$ & $++\left(44^{\circ} \mathrm{C}\right)$ & $+\left(42^{\circ} \mathrm{C}\right)$ & + & $3 \cdot 0$ & $1 \cdot 0$ & $43 \cdot 8$ & 205 \\
\hline
\end{tabular}

Table 3. Maximum growth rates $\left(\mu_{\max }\right)$ of E. coli W3110 and isogenic mutants

The $\mu_{\max }$ values were calculated from at least three batch cultures and the SD values were no more than \pm 0.03 .

\begin{tabular}{|c|c|c|c|c|}
\hline \multirow[t]{2}{*}{ Carbon source } & \multicolumn{4}{|c|}{$\mu_{\max }\left(h^{-1}\right)$} \\
\hline & $\begin{array}{c}\mathrm{W} 3110 \\
\left(3 l i p \mathrm{Nal}^{\mathrm{s}}\right)\end{array}$ & $\begin{array}{c}\text { JRG2931 } \\
\left(\text { llip }^{2} \mathrm{Nal}^{\mathrm{R}}\right)\end{array}$ & $\begin{array}{c}\text { JRG2932 } \\
\left(2 l i p \mathrm{Nal}^{\mathrm{R}}\right)\end{array}$ & $\begin{array}{c}\text { JRG2933 } \\
\left(3 l i p \mathrm{Nal}^{\mathrm{R}}\right)\end{array}$ \\
\hline Glucose $(20 \mathrm{mM})$ & 0.67 & $0 \cdot 31$ & $0 \cdot 45$ & $0 \cdot 64$ \\
\hline DL-Lactate $(10 \mathrm{mM})$ & 0.43 & $0 \cdot 36$ & $0 \cdot 41$ & 0.43 \\
\hline Succinate $(40 \mathrm{mM})$ & $0 \cdot 23$ & $0 \cdot 14$ & $0 \cdot 13$ & $0 \cdot 22$ \\
\hline Pyruvate $(40 \mathrm{mM})$ & $0 \cdot 33$ & $0 \cdot 30$ & 0.30 & $0 \cdot 31$ \\
\hline Acetate $(10 \mathrm{mM})$ & $0 \cdot 13$ & $0 \cdot 13$ & $0 \cdot 12$ & $0 \cdot 14$ \\
\hline Casamino acids $(0.3 \%)$ & $0 \cdot 49$ & 0.43 & 0.42 & $0 \cdot 46$ \\
\hline Yeast extract $(0.3 \%)$ & $0 \cdot 85$ & 0.75 & 0.78 & $0 \cdot 82$ \\
\hline
\end{tabular}

\section{Growth studies with batch cultures}

To investigate whether or not the lipoyl content of PDH complex affects the carbon flux into biomass and energy generation, the $\mu_{\max }$ values of the different strains were measured during growth in medium containing different carbon sources. It was predicted that the growth rates of different strains in media containing carbon sources which can be metabolized without the involvement of the PDH complex (e.g. acetate) should be similar. On the other hand, where the PDH complex performs a key role in the metabolism of a carbon source (e.g. glucose, succinate and pyruvate) the $\mu_{\max }$ values of the different strains might be affected. Growth was monitored for $10 \mathrm{~h}$ on medium containing the carbon source of interest. As expected, the $\mu_{\max }$ values of the wild-type (W3110) and reconstructed wild-type (JRG2933) were similar in all of the test media, but those of the isogenic 1lip and 2lip mutants (JRG2931 and JRG2932) growing in glucose, succinate and possibly lactate, exhibited lower $\mu_{\max }$ values (Table 3). This was particularly evident with the glucose-grown cultures, where the $\mu_{\max }$ values decreased sequentially with decreasing numbers of lipoyl domains per E2p chain. The number of lipoyl domains had little effect with acetate as the sole carbon source (Table 3). The $\mu_{\max }$ values were similar for all strains during growth on pyruvate, which is somewhat surprising in view of the central role of the PDH complex in pyruvate metabolism (Table 3). Possible reasons based on the inducing effects of exogenous pyruvate are considered in the Discussion.

\section{Complementation studies}

The possibility that the defective chromosomally encoded $\mathrm{PDH}$ complexes might be complemented by plasmidencoded 1lip- and 3lip-PDH complexes supplied in trans, was investigated by transforming JRG2931 (1lip) and JRG2933 (3lip) hosts with the multicopy plasmids pGS110 (1lip), pGS87 (3lip) and pBR322 (vector). The transformants were grown as batch cultures with $20 \mathrm{mM}$ glucose as sole carbon source and their growth rates are 
Table 4. Effects of plasmids encoding different PDH complexes on the maximum growth rates of isogenic $E$. coli strains

The isogenic mutants, JRG2933 (3lip) and JRG2931 (1lip) were transformed with multicopy plasmids: pBR322; pGS87 (3lip); and pGS110 (1lip). All strains were grown in triplicate in batch culture with medium containing glucose $(20 \mathrm{mM})$, and the average maximum growth rates $\left(\mu_{\mathrm{max}}\right)$ are listed; SD values were \pm 0.06

\begin{tabular}{|lcccc|}
\hline Host strain & \multicolumn{4}{c|}{$\boldsymbol{\mu}_{\max }$ for } \\
& No plasmid & $\begin{array}{c}\text { pBR322 } \\
\text { (vector) }\end{array}$ & pGS87 (3lip) & pGS110 (1lip) \\
\cline { 2 - 5 } & & & & \\
\hline W3110 (3lip) & 0.67 & - & - & - \\
JRG2933 (3lip) & 0.64 & 0.60 & 0.55 & 0.45 \\
JRG2931 (1lip) & 0.30 & 0.29 & 0.65 & 0.36 \\
\hline
\end{tabular}

compared in Table 4. Most strikingly, the $\mu_{\max }$ of JRG2931 (1lip) was restored to the wild-type level by pGS587 (3lip) but only marginally increased by pGS110 (1lip). Clearly, the metabolic debility of JRG2931 (1lip) is fully complemented by the presence of 3 lip-E2p subunits, but only partially complemented by the presence of extra 1lip-E2p subunits. In contrast, the growth of JRG2933 (3lip) was impaired by pGS587 (3lip) and more so by pGS110 (1lip), relative to pBR322 (Table 4). When interpreting these observations it has to be remembered that the chromosomally encoded E2p subunits are expressed from the pyruvate-sensitive $p d b$ promoter, whereas those encoded by the multicopy plasmids are expressed from the weak and apparently unregulated ace promoter (Fig. 1). Both sources presumably contribute, in different proportions depending on the strain, to the pool of E2p subunits from which 1lip-, 3lip- and a wide variety of hybrid-PDH complexes are assembled. Nevertheless, it appears that the unregulated contribution of extra 3lip-PDH complex subunits by pGS87 is somewhat debilitating for JRG2933 (3lip), whereas it enhances the growth of JRG2931 (1lip). The latter effect is presumably due both to the provision of wild-type subunits and to the ensuing limitation in the formation of chromosomally encoded 1lip-E2p subunits, caused by an intensification in repression of the pyruvate-sensitive $p d b$ promoter that will occur as pyruvate is processed more efficiently by the plasmid-encoded wild-type complex. It would be interesting to determine the total amounts of $\mathrm{PDH}$ complex and the relative contributions of chromosomeand plasmid-encoded E2p subunits in different transformant strains.

\section{Growth studies using continuous culture}

To investigate in more detail the physiological consequences imposed by selectively deleting lipoyl domains from the E2p chain, all strains were grown aerobically under carbon (glucose) limitation with and without a supplement of casamino acids $(0.01 \%)$. The cellular protein contents were essentially constant at all steady states and the substrate carbon was quantitatively recovered in biomass and $\mathrm{CO}_{2}$, i.e. $100 \%$ carbon balance was obtained. This was confirmed by the absence of overmetabolites in culture filtrates. All of the strains except JRG2931 (1lip) grew in unsupplemented and supplemented media, maintaining steady-states over a wide range of $D$ up to $0 \cdot 32 \mathrm{~h}^{-1}$ (Fig. 2). The same applied to JRG2931 (1lip) in supplemented medium, but without the supplement steady-states could only be maintained over a narrower range of $D$ (up to $0.09 \mathrm{~h}^{-1}$ ), wash-out occurring at $0 \cdot 10 \mathrm{~h}^{-1}$.

The carbon efficiencies (percentage carbon input into biomass) were relatively similar $(56 \cdot 2-60.4 \%)$ for the wild-type and mutant strains under all conditions except for JRG2931 (1lip) growing in unsupplemented medium, where a significant decrease $(48.4 \%)$ was observed (Table $5)$. Since the carbon balances at each of the steady-states maintained by JRG2931 (1lip) showed that substrate carbon is quantitatively recovered in the biomass and $\mathrm{CO}_{2}$ produced, the lower carbon efficiency indicates that there is a significant increase in the proportion of substrate carbon being used for energy generation. The glucose consumption rates $\left(q_{\mathrm{Glc}}\right)$ of all of the strains under all conditions, increased linearly with $D$ (Fig. 2). However, in the absence of the supplement, the maintenance energies $\left(m_{\mathrm{e}}\right)$ and the maximum growth yields $\left(Y_{\max }\right)$ decreased with decreasing numbers of lipoyl domains per E2p chain (JRG2931 1lip and JRG2932 2lip), but both parameters could be restored to those of the wild-type (W3110) and the reconstructed wild-type (JRG2933), by adding the casamino acids supplement (Fig. 2; Table 5). Similar results were obtained with JRG2931 (1lip) in glucose-limited medium supplemented with low concentrations of acetate (up to $0.1 \mathrm{mM}$; data not shown); steady-states could not be maintained at higher acetate concentrations.

\section{Competition experiments}

To confirm that bacteria with E2p subunits containing only one or two lipoyl domains per E2p chain are at a physiological disadvantage, equal numbers of wild-type E. coli W3110 (3lip Nal ${ }^{\mathrm{S}}$ ) and either JRG2931 (1lip Nal${ }^{\mathrm{R}}$ ), 




Fig. 2. Glucose consumption rates of $E$. coli W3110 and isogenic mutants. Steady-states were obtained over a range of $D$ values in the standard glucose-limited medium in the presence $(\square)$ and the absence $(\square)$ of casamino acid $(0.01 \%) ; \mathrm{pH}$ 6.9; dissolved $\mathrm{O}_{2} \geqslant 50 \%$ air saturation; $37^{\circ} \mathrm{C}$. (a) wild-type W3110 (3lip); (b) reconstructed wild-type JRG2933 (3lip); (c) isogenic mutant JRG2932 (2lip); (d) isogenic mutant JRG2931 (1lip).

JRG2932 (2lip $\mathrm{Nal}^{\mathbf{R}}$ ) or JRG2933 (3lip $\mathrm{Nal}^{\mathbf{R}}$ ) were inoculated into glucose-limiting medium in the same chemostat vessel. Growth under standard conditions of $\mathrm{pH}$, temperature and dissolved $\mathrm{O}_{2}$ was maintained for several hours to ensure that both bacterial strains had entered the exponential phase. The feed pump was then turned on and maintained at $D 0.075 \mathrm{~h}^{-1}$. The pairwise cultures were sampled immediately (zero generations) and at five-generation intervals thereafter, up to 50 generations. The fraction of the mutants $\left(\mathrm{Nal}^{\mathrm{R}}\right)$ to the total number of bacteria $\left(\mathrm{Nal}^{\mathrm{R}}+\mathrm{Nal}^{\mathrm{S}}\right)$ was plotted versus the number of generations to assess the retention of the 


\section{Table 5. Physiological parameters of glucose-limited chemostat cultures}

Chemostat cultures were grown in minimal medium with limiting glucose $(20 \mathrm{mM})$, at $\mathrm{pH} 6.9$ and $37^{\circ} \mathrm{C}$ with dissolved $\mathrm{O}_{2}$ at $\geqslant 50 \%$ air saturation, in the presence and the absence of casamino acids $(0.01 \%) . D$ was $0 \cdot 075-0.320 \mathrm{~h}^{-1}$ for all strains under all conditions except for JRG2931 growing without casamino acids, where the range was restricted to $0.050-0.090 \mathrm{~h}^{-1}$. The values were averaged for at least four independent steady-states, the sD values were no more than \pm 0.57 for carbon efficiency and total cellular protein content.

\begin{tabular}{|c|c|c|c|c|c|c|c|c|}
\hline \multirow[t]{2}{*}{ Strain } & \multicolumn{4}{|c|}{ Without casamino acids } & \multicolumn{4}{|c|}{ With casamino acids } \\
\hline & $\begin{array}{c}\text { Carbon } \\
\text { efficiency } \\
(\%)\end{array}$ & $\begin{array}{c}\text { Protein } \\
\text { content } \\
(\%)\end{array}$ & $m_{\mathrm{e}}^{*}$ & $\begin{array}{c}Y_{\max } \dagger \\
\text { (glucose) }\end{array}$ & $\begin{array}{c}\text { Carbon } \\
\text { efficiency } \\
(\%)\end{array}$ & $\begin{array}{c}\text { Protein } \\
\text { content } \\
(\%)\end{array}$ & $m_{e}^{*}$ & $\begin{array}{c}Y_{\max } \dagger \\
\text { (glucose) }\end{array}$ \\
\hline W3110 (3lip) & $60 \cdot 2$ & $56 \cdot 8$ & $0 \cdot 45$ & 103 & - & - & - & - \\
\hline JRG2931 (1lip) & $48 \cdot 4$ & $56 \cdot 4$ & $0 \cdot 13$ & 82 & $59 \cdot 4$ & $53 \cdot 7$ & 0.43 & 108 \\
\hline JRG2932 (2lip) & $57 \cdot 5$ & $56 \cdot 6$ & $0 \cdot 25$ & 93 & $56 \cdot 9$ & $53 \cdot 2$ & $0 \cdot 48$ & 109 \\
\hline JRG2933 (3lip) & $57 \cdot 4$ & $51 \cdot 3$ & $0 \cdot 45$ & 107 & $60 \cdot 4$ & $52 \cdot 0$ & $0 \cdot 44$ & 106 \\
\hline
\end{tabular}

* Maintenance energy in mmol ( $\mathrm{g}$ dry wt bacteria $)^{-1} \mathrm{~h}^{-1}$.

† Maximum growth yield on glucose in $\mathrm{g} \mathrm{mol}^{-1}$.

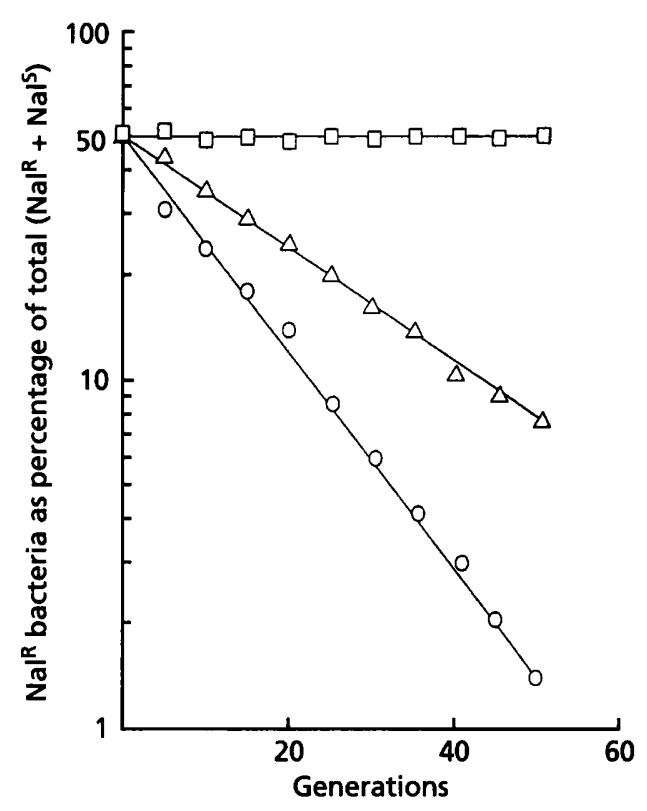

Fig. 3. Pairwise competition between wild-type and isogenic mutants in glucose-limited chemostat cultures $\left(D 0.075 \mathrm{~h}^{-1}\right)$. The rate of wash-out of non-competitive mutants ( $\left.\mathrm{Nal}^{R}\right)$ with increasing generations is indicated by the decline in the fraction of $\mathrm{Nal}^{\mathbb{R}}$ bacteria relative to the total $\left(\left.\mathrm{Nal}\right|^{\mathrm{R}}+\mathrm{Nal}{ }^{\mathrm{S}}\right)$. The fraction expressed as a percentage is plotted logarithmically versus the number of generations. Starting populations contained equal numbers of wild-type, W3110 (3lip) and either: $\square$, the reconstructed wild-type JRG2933 (3lip); $\triangle$, JRG2932 (2lip); or O, JRG2931 (1lip).

mutants (Fig. 3). In a control experiment, started with equal numbers of the wild-type (W3110, 3lip $\mathrm{Nal}^{\mathrm{S}}$ ) and reconstructed wild-type (JRG2933, 3lip $\mathrm{Nal}^{\mathrm{R}}$ ) bacteria, the fraction remained constant over 50 generations, indicating that the $\mathrm{Nal}^{\mathrm{R}}$ marker was not exerting any selectivity and that the reconstructed 3lip strain is truly equivalent to the wild-type parent. However, starting with equal numbers of the wild-type W3110 and either JRG2931 (1lip) or JRG2932 (2lip) bacteria, the proportion of $\mathrm{Nal}^{\mathbf{R}}$ bacteria decreased with increasing generations (Fig. 3). Moreover, the non-competitive 1lip population decreased more rapidly than the non-competitive 2 lip population when competing with W3110 at the same $D$. The calculated growth rates of the non-competitive populations were 0.071 and $0.067 \mathrm{~h}^{-1}$ for JRG2932 (2lip) and JRG2931 (1lip), respectively.

\section{DISCUSSION}

It was previously inferred from biochemical studies that contrary to evolutionary pressure, E. coli elaborates a PDH complex containing superfluous lipoyl domains. Here, the construction of isogenic derivatives of $E$. coli W3110 in which the chromosomal ace F gene was modified to encode one, two or three lipoyl domains per E2p chain, has provided an alternative approach to this problem. It allowed direct comparisons of the effects of lowering the lipoyl domain content of the PDH complex on the physiological competence of the intact organism under similar growth conditions. In consequence, it avoids problems stemming from differences in subunit stoichiometry or degree of lipoylation that are inherent in comparing the activities of purified complexes or complexes expressed from multicopy plasmids. It assumes only that the induction of the $p d h$ operon is identical for all strains, and this in turn is only important if the results are interpreted solely in terms of PDH complex activity or efficiency.

The growth rates of bacteria containing less than three lipoyl domains per E2p chain were adversely affected during growth on specific substrates in defined medium. The $\mu_{\max }$ values on carbon sources such as succinate, 
glucose and lactate, whose catabolism requires an active PDH complex, were reduced significantly when the lipoyl domain content was lowered. In contrast, similar values for $\mu_{\max }$ were observed with all strains during growth on acetate, the only substrate tested whose catabolism is not dependent on PDH complex activity.

The observation that all strains exhibit similar growth rates on pyruvate, was unexpected in view of the central role of the PDH complex in pyruvate metabolism, but it is explicable in terms of the established role of pyruvate as inducer of the $p d b \mathrm{R}-a c e E F-l p d$ operon. It has been observed previously that expression from the $p d b$ promoter is 3- to 4-fold higher during growth on pyruvate (40 $\mathrm{mM}$ ) compared to glucose (Quail et al., 1994). In vitro studies have further shown that transcription of the operon is repressed by the PdhR protein and relieved by pyruvate in a concentration-dependent manner over a $>1000$-fold range (Quail \& Guest, 1995). It is therefore quite conceivable that in the mutant strains, any limitation in C-flux to biomass or energy generation may be compensated by inducing higher levels of PDH complex expression when high concentrations of pyruvate are supplied exogenously, without affecting growth rate. During growth on glucose and succinate the intracellullar pyruvate concentrations are presumably insufficient to induce the compensating level of induction. Lactate probably represents an intermediate case, and higher lactate concentrations may have given results similar to those observed with pyruvate. Alternatively, or additionally, pyruvate might induce another pathway for the conversion of pyruvate to acetyl-CoA. These possibilities are being investigated using $p d b \mathrm{R}-l a c Z$ and $p d b \mathrm{R}-a c e E-$ lac $Z$ reporter fusions in the mutant strains, as well as direct tests with pyruvate-limited continuous cultures. The different effects of subunits from the plasmid-encoded 1 lip- and 3lip-PDH complexes on the growth rates of mutant and wild-type strains (Table 3), were also explicable in terms of an impairment conferred by the 1lip-E2p subunits and their expression from either pyruvate-regulated or unregulated promoters.

A more detailed study of the C-flux in different strains growing under controlled carbon (glucose)-limited conditions over a range of growth rates in the chemostat, supported and extended the results obtained with batch cultures. Steady-states were maintained over a wide range of $D$ (up to $0.32 \mathrm{~h}^{-1}$ ) except for JRG2931 (1lip). Despite the $\mu_{\max }$ of the latter strain being $0.31 \mathrm{~h}^{-1}$ in batch culture, steady-states could only be maintained at $D \leqslant 0.09 \mathrm{~h}^{-1}$ in a comparable medium. There is no obvious explanation for this apparent discrepancy. Studies now in progress with single-copy reporter fusions in the mutant strains should provide further insights into the degree of operon expression under different conditions, and a clearer understanding of the C-flux through the modified PDH complexes and its effect on overall C-flux. Despite the anomaly, substrate carbon was quantitatively recovered in biomass and $\mathrm{CO}_{2}$, the total cellular protein contents were similar, and there was no evidence for C-flux into overmetabolites or storage compounds, at all of the steadystates examined. However, the fraction of substrate carbon incorporated into biomass was lower in bacteria containing one lipoyl domain per E2p chain, JRG2931 (1lip), but not significantly lower in JRG2932 (2lip). This suggests that the $\mathrm{C}$-flux distribution between biomass formation and energy generation in JRG2931 (1lip) is readjusted in order to maximise the growth efficiency under carbon-limiting conditions. A corresponding increase in the rate of $\mathrm{CO}_{2}$ formation $\left(q_{\mathrm{CO} 2}\right)$ further supported this conclusion (data not shown). The glucose consumption rates $\left(q_{\mathrm{Glc}}\right)$ were linear with increasing dilution (growth) rate for all strains (Fig. 2). However, the values of $m_{\mathrm{e}}$ and $Y_{\max }$ fell as the lipoyl domain contents of the E2p chains were reduced, and the lower values could be restored to wild-type levels by the addition of casamino acids or acetate supplements (Table 5). Thus it is concluded that lowering the lipoyl domain content of the PDH complex has an adverse effect on growth under some conditions. This was confirmed in competition experiments in the chemostat where it was found that the wild-type (3lip) out-competes the isogenic mutants JRG2932 (2lip) and JRG2931 (1lip) in mixed populations. The wash-out rate was higher for the 1lip derivative than the 2 lip derivative, further confirming that the progressive removal of lipoyl domains (from three to two to one per E2p chain) is accompanied by a corresponding stepwise decline in the physiological proficiency of the host.

These results do not explain why the PDH complex of $E$. coli has three lipoyl domains per E2p chain, but they clearly demonstrate that all three lipoyl domains are required for efficient balanced growth on carbon substrates requiring the PDH complex for their catabolism. Because no gross effects on the specific activities of the isolated PDH complexes were observed previously, it is concluded that the debility imposed by lowering the lipoyl domain content is quite subtle, and may only be detected by sensitive kinetic analyses using substratelimiting conditions with carefully standardized complexes. Further studies on the physiological and metabolic effects of genetic modification of the structure and expression of the PDH complex are in progress.

\section{ACKNOWLEDGEMENTS}

The work was supported by a project grant from the Biotechnology Directorate of the Science and Engineering Research Council and a research studentship from the SERC. We are very grateful to Dr G. C. Russell for help and advice in constructing the aceF::kan ${ }^{\mathrm{R}}$ insertion mutant (JRG2930).

\section{REFERENCES}

Bergmeyer, H. U. \& Bernt, E. (1974). Determination of D-glucose with glucose oxidase and peroxidase. In Methods of Enzymatic Analysis, vol. 3, pp. 1205-1215. Edited by H. U. Bergmeyer. NY \& London: Academic Press.

Berman, J. N., Chen, G.-X., Hale, G. \& Perham, R. N. (1981). Lipoic acid residues in a take-over mechanism for the pyruvate dehydrogenase multienzyme complex of Escherichia coli. Biochem J 199, 513-520.

Brooke, A. G., Watling, E. M., Attwood, M. M. \& Tempest, D. W. (1989). Environmental control of metabolic fluxes in thermo- 
tolerant methylotrophic Bacillus strains. Arch Microbiol 151, 268-273.

Graham, L. D., Guest, J. R., Lewis, H. M., Miles, J. S., Packman, L. C., Perham, R. N. \& Radford, S.E. (1986). The pyruvate dehydrogenase multi-enzyme complex of Eschericbia coli: genetic reconstruction and functional analysis of the lipoyl domains. Pbil Trans R Soc Lond B 317, 391-404.

Guest, J. R., Lewis, H. M., Graham, L. D., Packman, L. C. \& Perham, R. N. (1985). Genetic reconstruction and functional analysis of the repeating lipoyl domains in the pyruvate dehydrogenase multienzyme complex of Escherichia coli. J Mol Biol 185, 743-754.

Guest, J. R., Angier, S. J. \& Russell, G. C. (1989). Structure, expression, and protein engineering of the pyruvate dehydrogenase complex of Eschericbia coli. Ann NY Acad Sci 573, 76-99.

Hamilton, C. M., Aldea, M., Washburn, B. K., Babitzke, P. \& Kushner, S. R. (1989). New method for generating deletions and gene replacements in Escherichia coli. J Bacteriol 171, 4617-4622.

Jannasch, H. W. (1969). Estimation of bacterial growth rates in natural waters. J Bacteriol 99, 156-160.

Lennox, E. S. (1955). Transduction of linked genetic characters of the host by bacteriophage P1. Virology 1, 190-206.

Machado, R. S., Clark, D. P. \& Guest, J. R. (1992). Construction and properties of pyruvate dehydrogenase complexes with up to nine lipoyl domains per lipoate acetyltransferase chain. FEMS Microbiol Lett 100, 243-248.

Machado, R. S., Guest, J. R. \& Williamson, M. P. (1993). Mobility in pyruvate dehydrogenase complexes with multiple lipoyl domains. FEBS Lett 323, 243-246.

Mattevi, A., de Kok, A. \& Perham, R. N. (1992). The pyruvate dehydrogenase multienzyme complex. Curr Opin Struct Biol 2, 877-887.

Miles, J. S., Guest, J. R., Radford, S. E. \& Perham, R. N. (1988). Investigation of the mechanism of active site coupling in the pyruvate dehydrogenase multienzyme complex of Escherichia coli by protein engineering. $J$ Mol Biol 202, 97-106.

Perham, R. N. (1991). Domains, motifs and linkers in 2-oxo acid dehydrogenase multienzyme complexes: a paradigm in the design of a multifunctional protein. Biochemistry 30, 8501-8512.

Quail, M. A. \& Guest, J. R. (1995). Purification, characterization and mode of action of $\mathrm{PdhR}$, the transcriptional repressor of the $p d b \mathrm{R}-a c e E F-l p d$ operon of Escherichia coli. Mol Microbiol 15, 519-529.

Quail, M. A., Haydon, D. J. \& Guest, J. R. (1994). The $p d b R-$ aceEF-lpd operon of Escherichia coli expresses the pyruvate dehydrogenase complex. Mol Microbiol 12, 95-104.

Russell, G. C. \& Guest, J. R. (1990). Overexpression of restructured pyruvate dehydrogenase complexes and site-directed mutagenesis of a potential active-site histidine residue. Biochem $J$ 269, 443-450.

Sambrook, J., Fritsch, E. F. \& Maniatis, T. (1989). Molecular Cloning: a Laboratory Manual, 2nd edn. Cold Spring Harbor, NY: Cold Spring Harbor Laboratory.

Stepp, L. R., Bleile, D. M., McRorie, D. K., Pettit, F. H. \& Reed, L. J. (1981). Use of trypsin and lipoamidase to study the role of lipoic acid moieties in the pyruvate and $\alpha$-ketoglutarate dehydrogenase complexes of Escherichia coli. Biochemistry 20, 4555-4560.

Turner, S. L., Russell, G. C., Williamson, M. P. \& Guest, J. R. (1993). Restructuring an interdomain linker in the dihydrolipoamide acetyltransferase component of the pyruvate dehydrogenase complex of Escherichia coli. Prot Eng 6, 101-108.

Vishniac, W. \& Santer, M. (1957). The Thiobacilli. Bacteriol Rev 21, 95-215.

Vogel, H. \& Bonner, D. M. (1956). A convenient growth medium for Escherichia coli and some other micro-organisms. Microb Genet Bull 13, 43-44.

Received 28 March 1995; accepted 19 April 1995. 